\title{
Una reseña sobre el test "Tamiz de problemas del lenguaje (TPL)"
}

\author{
A review of the "Test Language problems screen" \\ María Mercedes Pavez \\ Universidad de Chile \\ Pontificia Universidad Católica de Chile

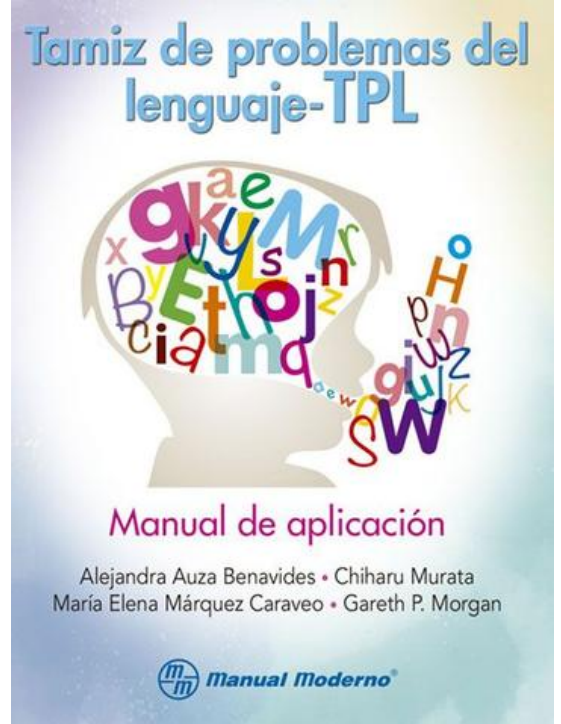

Autores: Alejandra Auza Benavides, Chiharu Murata,

María Elena Márquez Caraveo, Gareth P. Morgan

Editorial: El manual Moderno

Número de páginas: 64 páginas.

Año: 2018

ISBN: 978-607-448-650-6 
El texto presenta una prueba de tamizaje diseñada para detectar dificultades gramaticales en niños hispanohablantes de 3.0 a 6.11 años. Como tal, es un instrumento relevante que aborda una necesidad en el ámbito de los trastornos del desarrollo del lenguaje en hablantes de la lengua española. Su objetivo, según señalan los autores, es detectar en edades tempranas el trastorno específico del lenguaje (TEL), en particular con problemas expresivos, y guiar al niño con esta dificultad hacia la atención inmediata. Se contribuye así de modo importante a la detección temprana del trastorno, lo que es un aporte significativo considerando el impacto del TEL en la vida académica, especialmente en el aprendizaje de lecto-escritura y en la interacción social de los niños.

Como prueba de tamizaje centrada en el desempeño gramatical, consta de dos secciones breves. La primera de ellas aborda tareas de morfología dirigidas a evaluar específicamente partículas morfológicas en que los niños hispanohablantes suelen presentan dificultad: artículos, clíticos, preposiciones y palabras derivadas. Consta de trece preguntas. La segunda sección corresponde a una tarea de repetición de oraciones en la que se incorporan los mismos elementos morfológicos en oraciones con sintaxis compleja. Destacan los autores que este tipo de tarea implica de modo directo el procesamiento de la información y la memoria de trabajo, habilidades afectadas en los niños con trastorno expresivo del lenguaje. Esta sección incluye doce oraciones.

De este modo, la prueba es de corta duración y, por lo tanto, de rápida aplicación, cumpliendo así con una de las características relevantes de un instrumento de tamizaje.

Por otra parte, una prueba de esta naturaleza requiere un alto grado de certeza, validez y confiabilidad. El Tamiz de problemas del lenguaje-TPL cumple con creces con este requisito y presenta serios análisis estadísticos al respecto. Las características psicométricas del instrumento surgen a partir de la aplicación de la prueba a una muestra importante de niños mexicanos, monolingües hispanohablantes, con desarrollo típico del lenguaje y con trastorno del lenguaje.

En cuanto a materiales, el Tamiz de problemas de lenguaje-TPL consta de un manual de aplicación, hojas de respuesta, una libreta con estímulos visuales y un formato de resultados. 
El manual de aplicación contiene una Introducción en la que se describe en general la problemática que se abordará y la necesidad de una prueba para niños hispanohablantes con trastorno específico del lenguaje. Luego, en el manual se presenta la prueba propiamente tal con sus fundamentos teóricos, características y procedimientos de aplicación. A continuación, se exponen las características psicométricas de la prueba. Posteriormente, se ilustra la aplicación del instrumento en tres casos, recurso interesante y didáctico para los lectores. Se destaca en el análisis el enfoque cualitativo que se puede efectuar complementando la información cuantitativa que el instrumento entrega. Finalmente, en distintos apéndices se presentan hojas con el formato de la tarea de morfología y también con la repetición de oraciones; tabla de percentiles según la edad y calificación de la prueba; tabla con la probabilidad de tener TEL según el porcentaje obtenido en la prueba y, por último, una hoja o formato en que se sintetizan los resultados.

Por otra parte, la libreta con estímulos visuales contiene las preguntas que se formulan al niño en la tarea de morfología y dibujos en colores para facilitar la respuesta.

Así, en síntesis, en el texto Tamiz de problemas del lenguaje-TPL se presenta un instrumento que evidentemente es un aporte significativo para la detección temprana de los niños hispanohablantes con TEL expresivo. Se centra de modo específico en aspectos sensibles en el TEL como el desempeño gramatical en indicadores morfológicos y el procesamiento de la información implicando la memoria de trabajo. La prueba puede ser de gran utilidad para educadores, fonoaudiólogos y profesionales vinculados con estos niños. Sus características de tamizaje la hacen un instrumento de fácil aplicación en tiempo breve y sus estudios psicométricos proporcionan percentiles e información que facilita la identificación del niño. Todo ello respaldado por serios estudios de validez y confiabilidad. 